\title{
Relationship of cognitive function and adjustment difficulties among children and adolescents with dissociative disorder
}

\author{
Rajeev Ranjan, Manju Mehta, Rajesh Sagar, Siddharth Sarkar \\ Department of Psychiatry, All India Institute of Medical Sciences, New Delhi, India
}

\begin{abstract}
Background and Aims: Although it has been suggested that children and adolescents with dissociative disorder have some cognitive deficits, the association of these cognitive impairments with adjustment difficulties has not been evaluated. The present study aimed to assess the relationship between cognitive functioning and adjustment difficulties in children and adolescents with dissociative disorder. Methods: This cross-sectional, descriptive assessment was carried out in the outpatient setting of child and adolescent psychiatric service in a tertiary care hospital. Fifty newly diagnosed children and adolescents with dissociative disorder were included. The cognitive functions were assessed by varied neuropsychological tests, and Bell's adjustment inventory was used for assessing various domains of adjustment. Results: The mean age of the sample which comprised $40 \%$ males was $13.0( \pm 2.4)$ years. The mean intelligence quotient (IQ) of the sample was 90.6. Impairment in cognitive test was maximum for verbal working memory followed by sustained attention, visual learning and memory, and verbal retention and recall. Adjustment difficulties were greatest in the domains of self, followed by domains of health, school, and family. Significant association was found between the IQ and adjustment in school; visual learning and memory and adjustments in school and overall adjustment; and sustained attention and adjustment of health. Conclusions: Dissociative children have poor cognitive ability which may be related to poor adjustment scores.
\end{abstract}

Key words: Adjustment, children, cognition, conversion disorder, dissociative disorder

\section{Introduction}

Dissociative disorder is a common childhood psychiatric disorder encountered in Indian clinical practice. Several epidemiological and clinical studies conducted in India have found that condition is very common with a prevalence rate as high as $31 \%$ among inpatients and $15 \%$ among outpatients. ${ }^{[1]}$ The most common dissociative symptoms in India among children and adolescents are dissociative convulsions while motor weakness, amnesia, and aphonia are less commonly seen. ${ }^{[2-4]}$

\section{Address for correspondence:}

Dr. Rajeev Ranjan, Department of Psychiatry, All India Institute of Medical Sciences, Room No. 4096, Teaching Block,

New Delhi - 110 029, India.

E-mail: rajeevranjan0087@gmail.com

\begin{tabular}{|l|l|}
\hline \multicolumn{2}{|c|}{ Access this article online } \\
\hline Quick Response Code: & Website: \\
\hline & www.ruralneuropractice.com \\
\cline { 2 - 2 } & \\
\hline
\end{tabular}

Literature has shown a positive association between stressful life events and adjustment difficulties with subsequent dissociative symptoms. ${ }^{[5,6]}$ Children with dissociative disorder seem to lack adequate strategy to deal with these stressors effectively. ${ }^{[7,8]}$ The unresolved psychological conflict is then converted to physical symptoms which gain social acceptance and protect the child from conflict or painful memory. ${ }^{[9]}$ Particularly, Indian culture discourages direct expression of emotional distress, and the physical symptoms are more common way of expression. ${ }^{[10]}$ Stressors in children and adolescents with dissociative disorder may include day-to-day problems such as difficulties in school or family relationships, fights, scolding and punishment, some frightening experiences,

This is an open access article distributed under the terms of the Creative Commons Attribution-NonCommercial-ShareAlike 3.0 License, which allows others to remix, tweak, and build upon the work non-commercially, as long as the author is credited and the new creations are licensed under the identical terms.

For reprints contact: reprints@medknow.com

How to cite this article: Ranjan R, Mehta M, Sagar R, Sarkar S. Relationship of cognitive function and adjustment difficulties among children and adolescents with dissociative disorder. J Neurosci Rural Pract 2016;7:238-43. 
educational difficulties, sibling rivalry, sexual abuse, and adjustment problem with peers. ${ }^{[10-14]}$ Children with dissociative disorder also seem to have temperament characteristics of low activity, low emotionality, low rhythmicity, low attentivity, and low threshold of responsiveness. ${ }^{[15-17]}$

Although dissociation by definition affects cognition, very few studies have used neuropsychological measures to examine dissociative phenomena in children. Cognitive functioning has been reported as a major vulnerability factor in causing ineffective coping with stress. ${ }^{[18]}$ Among cognitive factors, both above-average and below-average intelligence has been cited as a factor in the etiology of dissociative disorder. ${ }^{[12]}$ Cromer et al. ${ }^{[19]}$ had examined the attentional correlates of dissociation in childhood. Consistent with the adult literature, higher levels of childhood dissociation were associated with deficits in tasks requiring inhibition, but not with tasks requiring primarily planning. ${ }^{[19]}$ Similar findings suggest that a failure to inhibit previous responses might contribute to the pathological memory manifestations of dissociation. ${ }^{[20]}$ Other studies also suggest that individuals showing higher levels of dissociation had more executive difficulties, and greater deficiencies in tasks of memory for context-dependent verbal material and visuospatial working memory. ${ }^{[21-23]}$

Though there are studies on identifiable psychosocial stressors and cognitive functioning among children and adolescents with dissociative disorder, no studies have attempted to know the relationship of cognitive functions with adjustment difficulties. Understanding the relationship of cognitive functions with adjustment difficulties may help in identifying key vulnerabilities and enabling focused intervention strategies for the varied profile of children with dissociative disorders. Thus, the present study was conducted to assess the cognitive functioning and adjustment difficulties among children and adolescents with dissociative disorder and to look for association between these domains.

\section{Methods}

\section{Setting and participants}

The study was conducted at the Child Guidance Clinic (CGC) of a tertiary care government teaching hospital in North India. The center gets both referred as well as nonreferred population. CGC is run by the Department of Psychiatry of the institute and caters to children in the age range of $4-16$ years. The children and adolescents are usually accompanied by their parents. CGC is manned by a team comprising consultant and trainee psychiatrists and consultant and trainee psychologists. Diagnosis is made according to International Classification of Diseases 10 (ICD 10) CDDG after detailed evaluation and discussion with the consultants. Pharmacological as well as psychotherapeutic treatment strategies are utilized, and management is carried out on inpatient or outpatient basis.

The present, cross-sectional, exploratory study was conducted in the outpatient of CGC. The inclusion criteria were diagnosis of dissociative disorder according to ICD 10 and age $8-16$ years. Patients with history of mental retardation or any organic psychiatric disorder were excluded. Patients were recruited after obtaining written informed consent from the parents and assent from the children. The study had the approval of the Ethics Committee of the Institute. Sample selection was done through nonpurposive nonrandom sampling.

\section{Study procedure}

The children and adolescents fulfilling the inclusion and exclusion criteria were recruited in the study. Patients were assessed using a semi-structured proforma which included sociodemographic and clinical profile. Malin's Intelligence Scale for Indian Children (MISIC) ${ }^{[24]}$ was for assessment of intelligence, "N-Back" task for verbal working memory, Rey's Auditory Verbal Learning Test (RAVLT) for verbal learning and memory, ${ }^{[25]}$ and memory for design test (MDT) for visual learning and memory, ${ }^{[26]}$ and color cancelation test (CCT) for sustained attention. ${ }^{[27]}$ Adjustment of different domains of functioning was measured through Bell's Adjustment Inventory. ${ }^{[28]}$ All the assessments were conducted by one of the study investigators. The assessments were carried out in one or two sessions, on days according to choice of the participants. The participants were allowed half to one hour break in between the different tasks as and when required.

\section{Instruments}

Malin's intelligence scale for Indian Children

This Indian validated adaptation of Weschler Intelligence Scale for children has both verbal and performance subscales. The verbal subscale has 5 tests - information, comprehension, arithmetic, digit span, analogies, and similarities while the performance subscale has 4 tests - picture completion, block design, object assembly, and coding. The subscale scores are generated by calculating the average of the tests in the subscale, and the mean intelligence quotient (IQ) is calculated by averaging the subscale scores. 


\section{"N-Back" task for verbal working memory}

This instrument developed by Smith and Jonides involves basic perceptual and sensorimotor functions. It consists of a "1 back task" and a " 2 back task." "1 back task" consists of list of phonemes; the list of phonemes is kept out of subjects view; each phoneme presents at the rate of 1 phoneme per second. The subject is required to respond in form of "yes" or "no," for phonetically similar and dissimilar sounds. In "2 back task," as each sound is presented, the subject has to decide whether or not it matched the sound that appeared 2 items back in sequence in which case the subject has to respond in term of "yes" or "no." In this condition, the subject must maintain representation of the 2 most recent sounds in memory to compare with the current one. Score was calculated on the basis of hits and misses.

\section{Rey's auditory verbal learning test for verbal learning and memory}

It is a measure of immediate memory, acquisition or new learning, retention, primacy and recency effect, and susceptibility to proactive and retroactive interference. It consists of 2 lists of 15 words each (3 words from 5 categories - body parts, animals, tools, vehicles, and household objects). Score for each trial is the number of words correctly recalled.

\section{Memory for design test for visual learning and memory}

The scale was developed by Jones-Gotman and Milner in 1986 and consists of 18 abstract designs. Designs are in order of increasing difficulty - 5 learning trials, each followed by immediate recalls and a delayed recall after a delay period of $60 \mathrm{~min}$.

\section{Color cancelation test for sustained attention}

This scale developed by developed by Kapur in 1974 measures sustained attention. It is also a measure of accurate visual scanning and activation and inhibition of rapid response. It consisted of 150 circles of 5 different colors: Red, yellow, blue, black, and gray. Subjects were required to cancel only 2 colors red or yellow as fast as can. Subjects were required to cancel digits. Time taken was noted, and error of omission and commission was noted. Score was calculated as total number of seconds taken plus number of errors (both omission and commission). More numbers of omission reflect poor visual scanning and poor selective attention, and more numbers of commissions reflect problem in inhibition of a rapid response.

\section{Bell's adjustment inventory}

The revised version was introduced by Hughes and Bell in 1962 and is used to discern adjustment in various domains. This 90-item scale answered in "yes" and "no" assesses adjustment in four domains of family, school, health, and self. Difficulty in adjustment in these four domains was scored by calculating number of "yes" responses. Each of the domains of the scale is transformed into 0-100 score.

\section{Statistical analysis}

Analysis was conducted using the SPSS for Windows (SPSS Inc, Chicago, IL, USA). Descriptive statistics was represented using means, standard deviations, frequencies, and percentages. For each of the cognitive tests, age and gender norms were used to discern whether the scores were normal or abnormal. To quantify the association in between two variables, Spearman's correlation coefficient was used. The $P<0.05$ was considered statistically significant and all the tests were two-tailed.

\section{Results}

A total of 56 patients were offered participation, out of which completed assessments were available in 50 patients. Four patients and/or their parents declined to participate while two left the study before the assessments could be completed. The demographic and clinical characteristics of the included patients are shown in Table 1 . The ratio of females to males in this population was 1.5. A majority of the children belonged to nuclear family from rural background and were irregular in going to school. Dissociative convulsion was the most common dissociative phenomenology observed, and 17 participants had more than one type of dissociative symptoms. Comorbid psychiatric diagnosis was present in $50 \%$ of the sample, with somatoform disorders being the most common psychiatric comorbidity observed (36\% of the sample).

The mean IQ of the sample was 90.6 as per MISIC, with 7 participants having IQ between 70 and 79 (borderline intelligence), 18 participants between 80 and 89 (dull average), 23 between 90 and 109 (average), and one each between 110-119 and 120-129, respectively (above average and superior). The verbal IQ was higher than performance IQ $(94.1 \pm 11.6$ vs. $87.1 \pm 10.8)$, but the difference was not significantly significant. The distribution of IQ scores across the various domains of MISIC is shown in Figure 1. The cognitive measures of the sample are shown in Table 2 . The maximum difficulty was observed in verbal working memory (N-back 2 ) and sustained attention as $38 \%$ and $66 \%$ of the sample had abnormal scores for N-back 2 and color cancelation task. 
Table 1: Demographic characteristics $(n=50)$

\begin{tabular}{|c|c|}
\hline Variable & $\begin{array}{l}\text { Mean }( \pm S D) \text { or } \\
\text { frequency }(\%)\end{array}$ \\
\hline$\overline{\text { Age }}$ & $13.0( \pm 2.4)$ \\
\hline \multicolumn{2}{|l|}{ Gender } \\
\hline Male & $20(40)$ \\
\hline Female & $30(60)$ \\
\hline \multicolumn{2}{|l|}{ Schooling } \\
\hline Up to $5^{\text {th }}$ grade & $15(30)$ \\
\hline $6^{\text {th }}-8^{\text {th }}$ grade & $28(56)$ \\
\hline Above $8^{\text {th }}$ grade & $7(14)$ \\
\hline \multicolumn{2}{|l|}{ Family type } \\
\hline Nuclear & $30(60)$ \\
\hline Others & $20(40)$ \\
\hline \multicolumn{2}{|l|}{ Background } \\
\hline Rural & $36(72)$ \\
\hline Urban & $14(28)$ \\
\hline \multicolumn{2}{|l|}{ Birth order } \\
\hline First & $16(32)$ \\
\hline Second & $18(36)$ \\
\hline Third and above & $16(32)$ \\
\hline \multicolumn{2}{|c|}{ Current attendance at school (last 1 month) } \\
\hline Regular & $10(20)$ \\
\hline Irregular & $40(80)$ \\
\hline \multicolumn{2}{|l|}{ Dissociative phenomenology ${ }^{\dagger}$} \\
\hline Convulsion & $44(88)$ \\
\hline Motor & $09(18)$ \\
\hline Trance and possession & $08(16)$ \\
\hline Anesthesia and sensation & $05(10)$ \\
\hline Amnesia & $01(2)$ \\
\hline Identity & $01(2)$ \\
\hline Stupor & $01(2)$ \\
\hline \multicolumn{2}{|l|}{ Psychiatric comorbidity } \\
\hline Somatoform disorders & $18(36)$ \\
\hline Anxiety disorder & $4(8)$ \\
\hline Depressive disorder & $2(4)$ \\
\hline Psychogenic hiccough & $1(2)$ \\
\hline
\end{tabular}

Some patients $(n=17)$ had more than one type dissociative symptoms. SD: Standard deviation

Table 2: Cognitive measures $(n=50)$

\begin{tabular}{lc}
\hline Variable & $\begin{array}{c}\boldsymbol{n} \text { below } \\
\text { cut-off' }(\%)\end{array}$ \\
\hline N-back-1 (verbal working memory) & $13(26)$ \\
N-back-2 (verbal working memory) & $19(38)$ \\
RAVLT (retention) & $6(12)$ \\
RAVLT (recall) & $8(16)$ \\
Memory for Design Test (visual learning and memory) & $14(28)$ \\
Color cancelation test (sustained attention) & $33(66)$ \\
\hline 'Based upon age and gender norms. ${ }^{[25-27]}$ RAVLT: Rey's Auditory Verbal Learning \\
Test
\end{tabular}

The adjustment difficulties in various domains were transformed into scores. The average adjustment difficulties score in the family domain was 22.9, school domain was 29.3, health domain was 33.1, and domain of self was 36.0. The correlation between various domains of adjustment and tests of cognition

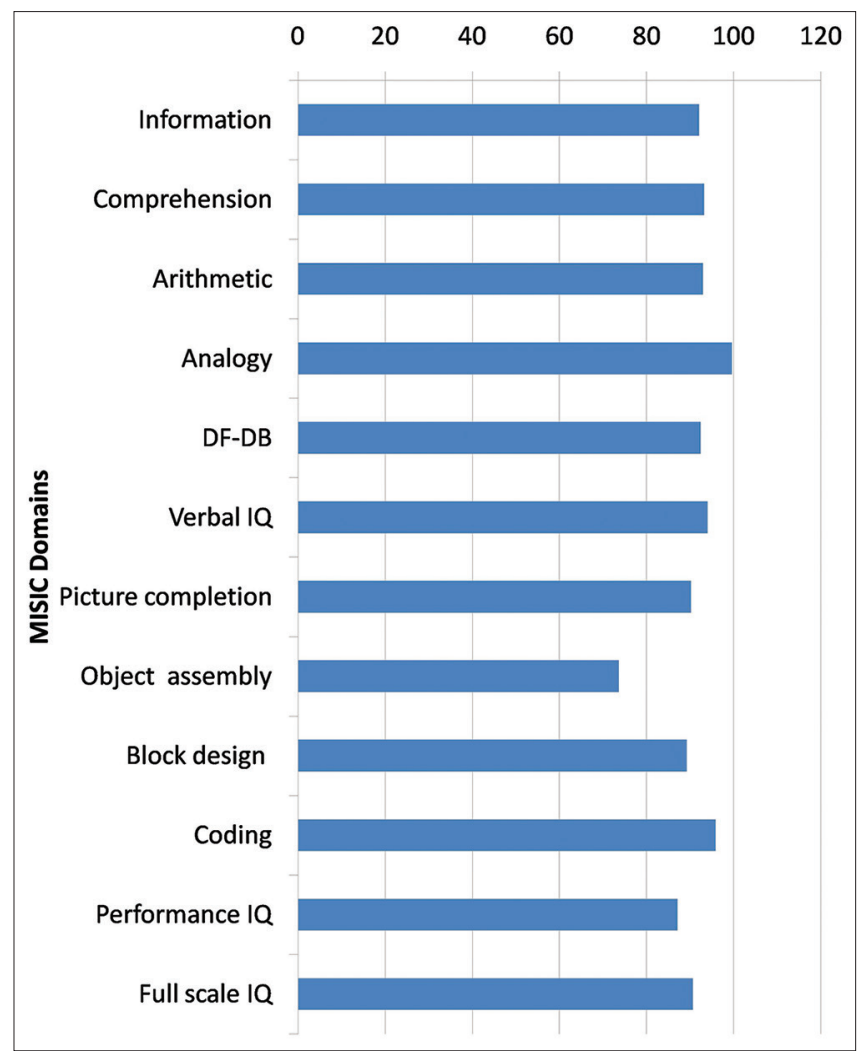

Figure 1: Malin's Intelligence Scale for Indian Children scores. Domain wise scores and full-scale scores. DF-DB: Digit forward digit backward, IQ: Intelligence quotient, MISIC: Malin's Intelligence Scale for Indian Children

is depicted in Table 3. Lower IQ was associated with poor adjustment in school (Spearman $r=-0.367$, $P=0.020)$. Abnormal scores in MDT delayed recall was associated with poor adjustment in school $(r=$ $-0.369, P=0.019)$ and overall adjustment $(r=-0.325$, $P=0.041)$. Finally, abnormality in sustained attention as per CCT was associated with poorer adjustment in health domains $(r=0.402, P=0.010)$.

\section{Discussion}

The present study explores the relationship of dissociative symptoms and cognitive functions in children and adolescents with dissociative disorders. The ratio of males to females was similar to literature from elsewhere, ${ }^{[16]}$ reflecting greater number of girls suffer from dissociation as compared to boys. The most common phenomenon of dissociation observed was dissociative convulsions, which is again the most common form of dissociation in the region and this specific age group..$^{[3,4,10]}$ Somatoform disorders were the most common comorbid disorders, suggesting that in many cases, psychological conflicts are dealt simultaneously through defenses of dissociation and somatization. 
Ranjan, et al.: Cognitive function and adjustment in dissociative disorder children

Table 3: Correlation of adjustment domains with cognitive functions $(n=50)$

\begin{tabular}{|c|c|c|c|c|c|}
\hline & \multicolumn{5}{|c|}{ Adjustment domains } \\
\hline & Family & School & Health & Self & Total \\
\hline IQ as per MISIC & $-0.269(0.094)$ & $-0.367(0.020)^{*}$ & $-0.071(0.663)$ & $-0.109(0.501)$ & $-0.231(0.152)$ \\
\hline N-back-1 (verbal working memory) & $-0.168(0.312)$ & $-0.057(0.736)$ & $0.125(0.455)$ & $0.027(0.873)$ & $-0.004(0.981)$ \\
\hline N-back-2 (verbal working memory) & $-0.095(0.561)$ & $-0.127(0.436)$ & $0.212(0.190)$ & $0.075(0.648)$ & $0.038(0.817)$ \\
\hline RAVLT (retention) & $-0.072(0.659)$ & $0.008(0.960)$ & $0.114(0.484)$ & $0.121(0.458)$ & $0.050(0.759)$ \\
\hline RAVLT (recall) & $-0.211(0.192)$ & $-0.157(0.334)$ & $-0.039(0.813)$ & $0.009(0.958)$ & $-0.108(0.509)$ \\
\hline Memory for Design Test (visual learning and memory) & $-0.262(0.103)$ & $-0.368(0.019)^{*}$ & $-0.308(0.053)$ & $-0.188(0.246)$ & $-0.325(0.041)^{\star}$ \\
\hline Color Cancelation Test (sustained attention) & $0.164(0.313)$ & $0.186(0.252)$ & $0.402(0.010)^{*}$ & $0.219(0.175)$ & $0.284(0.076)$ \\
\hline
\end{tabular}

Shown a Spearman correlation coefficient, ${ }^{*} P<0.05$, IQ: Intelligence quotient, MISIC: Malin's Intelligence Scale for Indian Children, RAVLT: Rey's Auditory Verbal Learning Test

The study suggests that the mean IQ of the sample was below the population norms, with greater deficit in performance aspects of intelligence. Previous literature suggests that children with dissociation have poor cognitive ability which results in ineffective coping with stress. ${ }^{[12]}$ The findings on the block design and object assembly tests imply that visuoconstructive and visual organization abilities are impaired. This suggests that ability for analysis, synthesis, gestalt perception, and reasoning ability are impaired. Poorer cognitive resources in these domains may translate into poor coping skills to handle demands of various stresses.

The present study suggests that children had comparatively greater difficulty in verbal working memory (N-back test) as compared to verbal retention and recall (RAVLT). This suggests that the participants found it difficult to inhibit previous response. This finding is similar to a previous study which suggests that a failure to inhibit previous responses might contribute to the pathological memory manifestations of dissociation. ${ }^{[20]}$ It has also been seen that childhood dissociation was associated with deficits in tasks requiring inhibition but not with tasks requiring primarily planning and strategy. ${ }^{[19]}$ A high proportion of children had scored abnormally in the color cancelation task involving selective attention. Previous studies suggest that dissociation was associated with lower sustained attention and varied between low and high dissociation. ${ }^{[22]}$

The present study suggests that greatest difficulties in adjustment were occurring in the domain of self. This suggests that personality factor has tremendous role in coping in these children in day to day life. Similar finding had been reported in different studies throughout review of literature. ${ }^{[15-17]}$ Lower IQ scores were significantly associated with the poor adjustment in school manifested in features such as poor academic performance and strained relationship with peers and teachers. Literature from elsewhere suggests that lower IQ has been associated with difficulties in adjustment to school environment. ${ }^{[29,30]}$ Poor visual learning and memory were associated with school maladjustment as well as overall adjustment difficulty. Possibly, visual memory holds special significance in planning and executing tasks, which would be quite helpful in efficient execution of day to day activities. Sustained attention abnormalities were associated with adjustment to the domain of health. This possibly could be attributed to exposure to health hazards among those who could not sustain attention. This exemplified by increased rates of falls and other minor injuries among children with attention deficit hyperkinetic disorder as compared to controls. ${ }^{[31,32]}$

The findings of the study should be contextualized in terms of the strengths and limitations. The strength of the study includes assessing for the $1^{\text {st }}$ time the relationship of cognitive function and adjustment domains in children and adolescents with dissociative disorder. Various cognitive domains were assessed using standard methodology. The limitations of the study include recruitment of a sample of convenience from a tertiary care center. Limited sample size precluded assessment of influence of different moderator variables on the adjustment and cognitive functioning. The adjustment was assessed through self-report of the participants, and further attempts to validate the same through proxy measures were not utilized. The study represents cross-sectional assessment and cannot comment on the changes in the relationship of cognitive functioning and adjustment over a period.

\section{Conclusion}

The study suggests that cognitive impairments and associated adjustment difficulties should be addressed in children and adolescents with dissociative disorder. Appropriate and timely intervention addressing cognitive deficits and related identifiable adjustment difficulties may possibly change the outcome of dissociative children, by improving adjustment to psychosocial stressors. Further studies are required in 
larger and control matched sample to consolidate the results of the present study. Future studies may look into association between cognitive function and adjustment difficulties over time using a longitudinal design so that natural evolution of the symptoms of dissociation in the context of interplay of cognition and stress can be clearly elucidated.

\section{Financial support and sponsorship \\ Nil.}

\section{Conflicts of interest}

There are no conflicts of interest.

\section{References}

1. Srinath S, Girimaji SC, Gururaj G, Seshadri S, Subbakrishna DK, Bhola $\mathrm{P}$, et al. Epidemiological study of child \& adolescent psychiatric disorders in urban \& rural areas of Bangalore, India. Indian J Med Res 2005;122:67-79.

2. Deka K, Chaudhury PK, Bora K, Kalita P. A study of clinical correlates and socio-demographic profile in conversion disorder. Indian J Psychiatry 2007;49:205-7.

3. Prabhuswamy M, Jairam R, Srinath S, Girimaji S, Seshadri SP. A systematic chart review of inpatient population with childhood dissociative disorder. J Indian Assoc Child Adolesc Ment Health 2006;2:72-7.

4. Malhi P, Singhi P. Clinical characteristics [correction of characterstics] and outcome of children and adolescents with conversion disorder. Indian Pediatr 2002;39:747-52.

5. van der Kolk BA, Roth S, Pelcovitz D, Sunday S, Spinazzola J. Disorders of extreme stress: The empirical foundation of a complex adaptation to trauma. J Trauma Stress 2005;18:389-99.

6. Gutiérrez Wang L, Cosden M, Bernal G. Dissociation as a mediator of posttraumatic symptoms in a Puerto Rican university sample. J Trauma Dissociation 2011;12:358-74.

7. Mora-Merchán JA. Coping strategies: Mediators of long-term effects in victims of bullying? Annu Clin Health Psychol 2006;2:15-25.

8. Shapiro DN, Kaplow JB, Amaya-Jackson L, Dodge KA. Behavioral markers of coping and psychiatric symptoms among sexually abused children. J Trauma Stress 2012;25:157-63.

9. Pehlivantürk B, Unal F. Conversion disorder in children and adolescents: A 4-year follow-up study. J Psychosom Res 2002;52:187-91.

10. Srinath S, Bharat S, Girimaji S, Seshadri S. Characteristics of a child inpatient population with hysteria in India. J Am Acad Child Adolesc Psychiatry 1993;32:822-5.

11. Sitholey P, Singh H. Hysterical symptoms and their causes in children. Indian J Soc Psychiatry 1986;2:160-74.

12. Sharma I, Giri D, Dutta A, Mazumder P. Psychosocial factors in children and adolescents with conversion disorder. J Indian Assoc Child Adolesc Ment Health 2005;1:n4.

13. Sharma P, Chaturvedi SK. Conversion disorder revisited. Acta Psychiatr Scand 1995;92:301-4.

14. Chu JA, Dill DL. Dissociative symptoms in relation to childhood physical and sexual abuse. Am J Psychiatry 1990;147:887-92.

15. Malhotra S, Varma VK, Verma SK. Temperament as determinant of phenomenology of childhood psychiatric disorders. Indian J Psychiatry 1986;28:263-76

16. Krishnakumar P, Sumesh P, Mathews L. Temperamental traits associated with conversion disorder. Indian Pediatr 2006;43:895-9.

17. Raghutaman G, Cherian A. Temperament of children and adolescents presenting with unexplained physcial symtoms. Indian J Psychiatry 2003;45:43-7.

18. Lazare A. Current concepts in psychiatry. Conversion symptoms. N Engl J Med 1981;305:745-8.

19. Cromer LD, Stevens C, DePrince AP, Pears K. The relationship between executive attention and dissociation in children. J Trauma Dissociation 2006;7:135-53.

20. Giesbrecht T, Merckelbach H, Geraerts E, Smeets E. Dissociation in undergraduate students: Disruptions in executive functioning. J Nerv Ment Dis 2004;192:567-9.

21. Bruce AS, Ray WJ, Bruce JM, Arnett PA, Carlson RA. The relationship between executive functioning and dissociation. J Clin Exp Neuropsychol 2007;29:626-33.

22. DePrince AP, Weinzierl KM, Combs MD. Stroop performance, dissociation, and trauma exposure in a community sample of children. J Trauma Dissociation 2008;9:209-23.

23. Amrhein C, Hengmith S, Maragkos M, Hennig-Fast K. Neuropsychological characteristics of highly dissociative healthy individuals. J Trauma Dissociation 2008;9:525-42.

24. Malin AJ. Malin's intelligence scale for Indian children. Child Guidance Centre, Nagpur, India, 1969.

25. Schmidt M. Rey Auditory Verbal Learning Test: A Handbook. Los Angeles: Western Psychological Services; 1996.

26. Graham FK, Kendall BS. Memory-for-designs test: Revised general manual. Percept Mot Skills 1960;11:147-88.

27. Kapur M. Measurement of Organic Brain Dysfunction. PhD Thesis. Bangalore: Bangalore University; 1974.

28. Bell HM. The Adjustment Inventory: Revised Student Form. Palo Alto, California: Consulting Psychologists Press Inc.; 1962.

29. Campbell FA, Ramey CT. Effects of early intervention on intellectual and academic achievement: A follow-up study of children from low-income families. Child Dev 1994;65 2 Spec No: 684-98.

30. Hutchinson EA, De Luca CR, Doyle LW, Roberts G, Anderson PJ; Victorian Infant Collaborative Study Group. School-age outcomes of extremely preterm or extremely low birth weight children. Pediatrics 2013;131:e1053-61.

31. Pastor PN, Reuben CA. Identified attention-deficit/hyperactivity disorder and medically attended, nonfatal injuries: US school-age children, 1997-2002. Ambul Pediatr 2006;6:38-44.

32. Merrill RM, Lyon JL, Baker RK, Gren LH. Attention deficit hyperactivity disorder and increased risk of injury. Adv Med Sci 2009;54:20-6. 